\section{A NICE mess}

History tells us that whenever there is excessive central control, there is always a possibility of stifling creativity, flexibility and - potentially — growth. The relative economic success of the capitalist model versus the communist is one worth reflecting on. Psychiatry in many ways is probably a branch of medicine where a degree of flexibility and creativity play an integral part. Flexibility does not necessarily mean taking risks. A proscriptive approach can adversely affect the way psychiatric teams work; by enforcing guidelines, clinicians may feel pressurized to take an algorithmic approach, leading to intellectual redundancy when practicing the art and science of psychiatry.

When the National Institute for Clinical Excellence (NICE) was conceived by the Department of Health in the late 1990s, it was expected to raise clinical and social care standards, standardize delivery of care and reduce local variations so that NHS organizations could benchmark their performance against it. NICE - and its reincarnation, the National Institute for Health and Clinical Excellence, also called NICE - is an independent organization which aims to promote health by prevention and treatment of diseases. It has recently been plagued by controversies and the early promise has dimmed somewhat. Recent guidelines on mental health have also attracted controversies.

The interpretation of these guidelines can also lead to confusion. Guidelines are meant to be just that. The rubric in all NICE documents states the guidance is 'not a substitute for professional knowledge and clinical judgement' and they 'do not override the individual responsibility of healthcare professionals to make appropriate decisions'. Unfortunately, guidelines may gain the status of indisputable recommendations, not least in primary care trusts where managers control the purse-strings. Furthermore, although NICE guidelines can be very helpful in guiding clinicians and patients, they focus on the clinical problem and cannot take into account various other factors (e.g. physical and psychological co-morbidities, social and cultural issues) that make each patient unique. These nuances are mostly lost in the environment of clinical trials, making it counter-intuitive to rigorously translate evidence to the individual, and are often impossible to take into account while formulating guidelines despite playing a major role in clinical judgement, decision making, care planning and the ultimate clinical outcome.

\section{INTERPRETATION OF EVIDENCE}

Some of the earlier NICE guidelines (e.g. those on schizophrenia) were generally well received. They were seen as practical and helpful. According to a 2005 study by
Gaebel et al.,1 the NICE schizophrenia guidelines were judged the most sound on methodological quality and implementability of leading internationally accepted guidelines on this disorder.

An interesting example of the poor quality of evidence used to make recommendations is the depression guidelines. Only four of the 32 recommendations in the full guidance were based on grade 'A' evidence (i.e. supported by at least one adequate quality randomized controlled trial), and the majority of recommendations were supported by grade ' $\mathrm{C}$ ' recommendations (i.e. based only on expert committee report or respected opinion). This is hardly evidence-based practice as envisaged by David Sackett. ${ }^{2}$ The contentious advice about restricting the use of venlafaxine to specialist care was only based on grade $\mathrm{C}$ evidence $^{3}$ yet had far-reaching consequences for depression management.

With some guidelines it is not easy to determine the level of evidence used in decision making. For example, the restriction on the use of maintenance $\mathrm{ECT}^{4}$ is not based on any randomized trial data and makes the classic error of assuming that absence of evidence equates to absence of effect. In fact maintenance ECT has been shown to be effective in preventing relapse of chronic depression. ${ }^{5}$ Another issue is lack of quality control of evidence. The NICE guidance on dementia treatment gave a lot of weight to the AD 2000 study, ${ }^{6}$ subsequently criticized for its methodological flaws and high attrition rate, which cast doubt on the efficacy of cholinesterase inhibitors. ${ }^{7}$

\section{FAIRNESS}

Another concern is the constitution of the panels making decisions for NICE. For example, the NICE appraisal panel for anti-dementia drugs did not include any geriatric psychiatrists among its 32 members, but did include an anaesthetist, a nephrologist, a neonatal paediatrician and a healthy smattering of NHS managers. Four geriatric psychiatrists were invited to give opinions to the appraisal committee. It may appear reasonable to restrict individuals most directly involved in dementia care, presumably because they may hold partisan views. However, is any member of such a committee free from such bias? Restricting an expensive drug in one sphere may make more money available for drugs in other specialties, including those of the panel members.

\section{COST AGENDA}

NICE are quite open about cost limitation on their agenda, which we consider reasonable provided the methods of cost-benefit analysis are robust. However, primary care trusts may interpret guidance differently, neutralizing one of the main aims of NICE - to reduce discrepancy in 
availability of drugs in different areas. When new but relatively expensive drugs such as bevacizumab and cetuximab (for colorectal cancer) or Herceptin (for breast cancer) are deemed not cost-effective enough to be prescribed by the NHS it leads to the possibility of a two-tier system. Those who can afford these treatments (and/or have insurance cover) can seek private prescriptions or could move to Scotland where more drugs are available (for example Velcade, a drug for myeloma). Politicians also seem to be drawn into these cost debates which can further hamper the independence of NICE.

\section{SPEED OF DECISIONS}

In an ever-changing environment of newer treatments and an evolving evidence base, NICE seems to find it difficult to keep pace. For example, the novel antipsychotic aripiprazole was introduced shortly after publication of the schizophrenia guidelines. Appraisals and updates every few years are not sufficient. Wary managers of trusts which have to deliver annual cost improvement plans (what we would call budget cuts) may also see this as an opportunity to stall inclusion of potentially more expensive but effective new treatments on their lists, leaving many clinicians and patients feeling short-changed. Regular updating of the guidelines is also likely to make all stakeholders feel more confident about the whole NICE review process, as this would enhance greater and regular consensus generation with greater malleability.

\section{LEGAL IMPLICATIONS}

The law of clinical negligence also shows signs of change. Traditionally, a claimant's case fails if a doctor's actions are Bolam-defensible (i.e. in accord with the actions that would have been taken by a body of medical practitioners). However, as discussed before in the JRSM (JRSM 2003;96: 133-138), actions now may also have to be Bolithojustifiable (i.e. does the action have a logical basis, and has the doctor weighed up the risks and benefits properly). ${ }^{8}$ In other words, there may be a requirement for the defendant doctor to explain why a specific action was taken, or not, and to justify the action or inaction. If clinical guidelines are meant to enhance the quality of clinical care, then the courts might enquire why such guidelines were not followed and whether a decision not to follow them was reasonable.

\section{CONCLUSION}

One size cannot fit all. The government and NICE have to realize their shortcomings before expecting all involved to accept their pronouncements without questioning. Proper consultation, seeing guidelines only as guidelines and not as rules set in stone, and flexible approaches may be the way forward.

Competing interests None declared.

Guarantor Susham Gupta.

Contributorship SG and JW jointly conceived the article. SG wrote the initial draft. SG and JW both amended the text and approved the final version of the manuscript.

\section{Susham Gupta ${ }^{1}$ James Warner ${ }^{2}$}

${ }^{1} \mathrm{SpR}$ in Psychiatry, ${ }^{2}$ Consultant Psychiatrist, Central North and West London NHS Foundation Trust, Nightingale Unit, St Charles Hospital, Exmoor Street, London W6 8R

Correspondence to: Susham Gupta

Email: sushamgupta@yahoo.com

\section{REFERENCES}

1 Gaebel W, Weinmann S, Sartorius N, Rutz W, McIntyre JS. Schizophrenia practice guidelines: international survey and comparison. BrJ Psych 2005;187:248-55

2 Sackett DL, Rosenberg WMC, Gray JAM, Haynes RB, Richardson WS. Evidence-based medicine: what it is and what it isn't. BMJ 1996;312: $71-2$

3 National Institute for Clinical Excellence. Depression: Management of Depression in Primary and Secondary Care. Clinical Guideline 23. London: NICE, 2004

4 National Institute for Clinical Excellence. Guidance in the Use of Electroconvulsive Therapy (Technology Appraisal Guidance 59. London: NICE, 2003

5 Rabheru K, Persad E. A review of continuation and maintenance electroconvulsive therapy. Can J Psych 1997;42:476-84

6 Courtney C, Farrell D, Gray R, et al. Long-term donepezil treatment in 565 patients with Alzheimer's disease (AD2000): randomized doubleblind trial. Lancet 2004:363:2105-15

7 Holmes C, Burns A, Passmore P, Forsyth D, Wilkinson D. AD2000: design and conclusions. Lancet 2004;364:1213-4

8 Samanta A, Samanta J, Gunn M. Legal considerations of clinical guidelines: will NICE make a difference? J R Soc Med 2003;96:133-8 